\title{
A linguagem da bula: um estudo de estruturas linguísticas do gênero
}

\author{
The drug leaflet and its language: a study on the linguistic structures of genre
}

Carmelita Minelio da Silva Amorim¹, Lúcia Helena Peyroton da Rocha² ${ }^{2}$ Maria José Costa ${ }^{3}$

1 Doutora em Linguística. Professora da Universidade Federal do Espírito Santo. Projeto rito Santo. Projeto de Pesquisa em Linguagens.

2 Doutora em Linguística. Professora da Universidade Federal do Espírito Santo. Projeto de Pesquisa em Linguagens.

Inpeyroton@gmail.com

Mestre em Linguística. Atua como Presidente do Instituto Alcina Costa de Apoio

Produção Pedagógica.

mariajose.costa@gmail.com
RESUMO: Este artigo apresenta um estudo de construções de passiva presentes em bulas de medicamentos elaboradas no Brasil, considerando a complexidade sintática, semântica e pragmática da língua portuguesa em uso, especialmente os esforços de seus produtores para atenderem às novas exigências da Agência Nacional de Vigilância Sanitária (ANVISA), regulamentação normatizada no ano de 2009, que demanda, dentre outros aspectos, o uso de uma linguagem mais clara e objetiva, visando garantir aos leitores o acesso à informação segura e adequada para uso racional dos medicamentos. 0 objetivo da pesquisa é analisar a língua em uso no gênero bula, procurando especificamente identificar e discutir: a) as diferentes estruturas linguísticas presentes no texto das bulas selecionadas; b) se e quando são adotadas estratégias de apagamento do agente. Considerouse como pressuposto que, em textos mais formais e não ficcionais, como é o caso do gênero bula, seria mais frequente a utilização de estruturas passivas, com apagamento do agente motivado pela facilidade de recuperação das informações com base no conhecimento pragmático geral das pessoas. Na fundamentação teórica, partiu-se de uma visão histórica, com reflexões sobre a abordagem tradicional, passando-se em seguida pela abordagem formalista da língua, e adotando-se como referencial o Funcionalismo Linguístico de Givón (1984, 1995), Shibatani (1985) e Furtado da Cunha (2000), além de contribuições da Linguística Textual para análise do gênero. O corpus para a pesquisa foi selecionado de textos de bulas coletadas digitalmente do bulário eletrônico disponibilizado para acesso no portal da ANVISA e também de meios físicos, em caixas de medicamentos encontrados em residências ou farmácias. Escolheu-se analisar o texto de bulas dos medicamentos de uso mais corrente no Brasil, tomando como referência aqueles citados no portal da saúde e relacionados para venda em farmácia popular, que foram selecionados, aleatoriamente, dentre os mais conhecidos e comumente encontrados nos lares brasileiros, dando-se prioridade, no presente estudo, às bulas elaboradas para serem lidas por pacientes, ou seja, o público leigo.

PalaVRas-chave: Construções de Passiva; Gênero Textual Bula; Funcionalismo Linguístico.

ABSTRACT: This article presents a study of passive constructions in drug leaflets produced in Brazil, considering the syntactic, semantic and pragmatic complexity of the Portuguese language in use, especially the efforts of their producers to meet the new requirements of the National Health Surveillance Agency (ANVISA), regulations standardized in 2009, which require, among other things, the use of a clearer and more objective language, ensuring that readers have access to safe and adequate information for the rational use of drugs. The objective of this research is to analyze the language used in the drug leaflet genre, attempting specifically to identify and discuss: a) the different language structures in the text of the selected leaflets; b) if and when agent deletion strategies are adopted. It was taken as an assumption that, in more formal and nonfiction texts, as it is the 
case of the drug leaflet genre, the use of passive structures would be more frequent, with the deletion of the agent motivated by the easy retrieval of information made by people, based on their general pragmatic knowledge. The theoretical framework used starts with a historical overview with reflections on the traditional approach, moving to the formalistic approach to language, and adopting as reference the Linguistic Functionalism of Givón $(1979,1984,1995)$, Shibatani (1985) and Furtado da Cunha (2000), as well as contributions from Textual Linguistics for the analysis of the genre. The corpus for the research was selected from the texts of leaflets collected digitally in the electronic list of drug leaflets made available in the ANVISA website as well as collected physically in drug packages found at home or in drugstores. We have decided to analyze the text of leaflets of the most common drugs in Brazil, taking as a standard those mentioned in the health website and listed for sale in popular drugstores, selected randomly among the best known and most easily found in Brazilian homes, with priority being given, in this study, to the leaflets designed to be read by patients, i.e., the lay public.

KEYwords: Passive Constructions; Textual Genre; Linguistic Functionalism.

\section{Introdução}

estudo de fenômenos linguísticos tem como base determinada visão de língua, que norteia tanto o referencial teórico quanto o tipo de análise adotados. Para este trabalho ${ }^{1}$, partimos da concepção de língua como um instrumento de comunicação, analisável como um fenômeno interativo que se adapta continuamente às necessidades comunicativas e cujo uso influencia na alteração e/ou fixação de determinadas estruturas (GIVÓN, 1995).

Nesse contexto, a descrição do comportamento linguístico é entendida como um processo e não como um estado ou um produto, ou uma tradição histórica. A impossibilidade de explicar a língua, de modo satisfatório, com referência a variáveis linguísticas, apenas, demonstra a necessidade de parâmetros extralinguísticos ligados ao modo como percebemos o mundo que nos rodeia, e como podemos utilizar os recursos linguísticos disponíveis para conceituar as nossas experiências e para nos comunicarmos com êxito (HEINE, 1993, p. 3).

${ }^{1}$ Este artigo foi originalmente enviado para publicação nos Anais do Congresso Internacional da ABRALIN, em 2013, mas não houve publicação de anais.
O objetivo da pesquisa é analisar a língua em uso no gênero bula, procurando especificamente identificar e discutir: a) as diferentes estruturas linguísticas presentes no texto das bulas selecionadas; b) se e quando são adotadas estratégias de apagamento do agente.

Neste trabalho, partimos da hipótese de que, em textos mais formais e não ficcionais, como é o caso do gênero bula, seria mais frequente a utilização de estruturas de passiva, com apagamento do agente motivado pela facilidade de recuperação das informações com base no conhecimento pragmático geral das pessoas (conhecimento enciclopédico e de mundo).

Para a discussão teórica, fazemos um percurso, partindo da gramática tradicional, passando pela abordagem formalista e apresentando os pressupostos da perspectiva funcionalista que norteia nossa análise dos dados.

\section{Estrutura de passiva na perspectiva tradicional}

A estrutura de passiva tem sido tratada, nas gramáticas tradicionais, de modo superficial, incompleto e descontextualizado. Esse tipo de tratamento deve-se à concepção de língua adotada pelos compêndios gramaticais, que 
consideram a língua um sistema abstrato e fechado, cuja compreensão pode ser obtida tomando frases descontextualizadas como unidades de análise.

Na perspectiva tradicional, a construção passiva é considerada como um fenômeno de voz e estrutura-se de duas formas: (1) passiva analítica, em que o paciente da ação verbal é o sujeito da oração, formada normalmente pelo verbo auxiliar ser + particípio passado de verbos transitivos diretos + preposição por (ou de) + agente da passiva. Exemplos: A casa foi construída por este engenheiro / Ela é estimada de todos; (2) passiva sintética, em que há a ocorrência do pronome clítico se com verbos transitivos diretos na terceira pessoa seguidos de um sintagma nominal (SN) com valor semântico de paciente. Exemplo: Alugam-se casas.

Bechara (1999, p. 222) menciona os verbos estar e ficar como possibilidades de formarem a estrutura de passiva, porém não apresenta exemplos com esses dois verbos, mas estabelece uma diferença entre passividade e voz passiva, apresentando como exemplo de passividade: Os criminosos receberam o castigo merecido. Ao fazer a distinção, o autor não deixa muito claro qual critério adotou, o que poderia causar dúvidas aos consulentes, uma vez que a frase arrolada poderia ser convertida em: $O$ castigo merecido foi recebido pelos criminosos, embora essa não pareça ser uma opção da qual o usuário da língua se valesse diante de uma situação em que "criminosos fossem castigados merecidamente". Além disso, não se trata de um verbo de ação, já que os criminosos "sofrem" com a ação praticada por alguém, sendo, portanto, o paciente; não o agente.

Em relação ao agente da passiva, o autor destaca que nem todo termo introduzido pela preposição por tem a função de agente, principalmente se apresentar traço não-animado, referente à coisa, devendo ser classificado como adjunto circunstancial de causa ou meio. Nesses casos, por é comutável com outra preposição ou com locuções do tipo por causa de. Exemplos: $O$ artista foi elogiado pela sua técnica / Os ladrões foram encontrados pela denúncia anônima (BECHARA, 1999, p. 435).

Said Ali (1964, p. 95) destaca que alguns verbos intransitivos podem construir orações em voz passiva desde que tenham por complemento um nome regido pela preposição $a$. Exemplo: Os meninos obedecem ao mestre / $O$ mestre é obedecido. A concepção de (in)transitividade defendida por Said Ali (1964) se distancia de outras proposições tradicionais, que classificam o verbo obedecer como transitivo indireto. Ainda que a maioria dos gramáticos advogue no sentido de que só verbos transitivos diretos podem ter uma passiva correspondente, em jornais e revistas, há exemplos de uso de verbos transitivos indiretos em estrutura de passiva, como se vê em exemplos arrolados por Ignácio (2002, p. 50-51): A atual legislação não é obedecida por nenhum dos concorrentes, que organizam suas campanhas num ambiente de cumplicidade mútua e impunidade geral (Revista Veja).

Apontando para uma perspectiva menos tradicional, Abreu (2003, p. 117-120) divide a voz passiva em analítica e pronominal. A passiva analítica configura-se com o verbo auxiliar ser, passando o objeto direto da voz ativa a ocupar a função de sujeito e o sujeito da ativa sendo transferido para o predicado, precedido, em geral, pela preposição por, como complemento agente da voz passiva (Ana Paula fechou as portas $>$ As portas foram fechadas por Ana Paula). A passiva pronominal ocorre com o pronome se (Pinturas preciosas salvaram-se, durante o ataque da máfia em Florença, graças às cortinas de vidro blindado) e não há possibilidade de o sujeito ser agente. Outra característica da voz pronominal é a ausência completa do agente da passiva.

O autor destaca que nem todas as construções ativas possuem passivas correspondentes. Em Maria levou um tiro, Maria é paciente, o que impossibilita a transformação para a passiva ( ${ }^{*}$ Um tiro foi levado por Maria). Para Abreu (2003), isso se dá porque a "ativa" em questão não é prototípica. 
A ativa precisa de sujeito agente (Maria levou a mala $>$ A mala foi levada por Maria).

Abreu (2003) destaca que análogas à voz passiva pronominal são as construções com verbos intransitivos (Anda-se muito de bicicleta em cidades planas), em que o agente experienciador é indeterminado, sendo apenas pressuposto.

\section{Estrutura de passiva na perspectiva formalista}

Na abordagem formalista, mais especificamente com os desenvolvimentos da Gramática Gerativa de Chomsky (1957), destacam-se as seguintes características das expressões passivas: a) o sujeito gramatical de uma passiva é o objeto da ativa correspondente; b) o sujeito da contraparte ativa é expresso na passiva como um adjunto agentivo ou não expresso; c) o verbo da construção passiva corresponde ao verbo da ativa com uma marcação especial de voz passiva.

Na tentativa de explicar a relação entre o objeto lógico do verbo das sentenças ativas e o sujeito das passivas, Chomsky (1981) formulou a hipótese de que a estrutura ativa estaria latente na estrutura de passiva. Nesse ponto, a perspectiva gerativa compartilha a ideia, herdada da tradição gramatical latina, de que estruturas ativas e passivas que possuem o mesmo verbo são sinônimas.

Entretanto, Langacker (1990) afirma que essa sinonímia é equivocada, pois é apenas aparente e decorre da ideia de que as estruturas ativas e passivas se referem ao mesmo evento objetivo no mundo. $\mathrm{O}$ autor destaca que as estruturas são objetos linguísticos e não correspondem diretamente aos acontecimentos do mundo real, mas sim a 'conceptualizações' dos falantes sobre esses acontecimentos. Desse modo, não são iguais em termos semânticos e nem mesmo em termos pragmáticos, uma vez que o falante ao utilizar uma ou outra estrutura evidencia intenções e também motivações de ordens diversas.

A nossa posição se coaduna com a de Langacker (1990), uma vez que seria ingênuo pensar que usar a estrutura ativa ou passiva é uma simples questão sinonímica; contrariamente, a escolha por uma, no lugar da outra envolve indubitavelmente o intuito de realçar um elemento em detrimento do outro. Haja vista que ao proferir a frase: “Lara abriu a janela”, o falante coloca em perspectiva principal o sujeito da ação de abrir; ou seja, realça o agente: Lara; enquanto em: "A janela foi aberta por Lara", há uma ênfase naquilo que foi afetado (a janela). Ademais, o uso da passiva permite que o falante não coloque em evidência os principais responsáveis por uma determinada ação, ou por ser desnecessário evidenciá-lo ou por ser redundante fazê-lo.

Para a Gramática Gerativa, a estrutura de passiva é entendida como uma operação essencialmente gramatical, sintática e abstrata, que se enquadra numa regra transformacional. Os exemplos de não correspondência entre estruturas ativas e passivas (João tem uma casa / *Uma casa é tida por João) são considerados como exceções ou idiossincrasias da língua e devem ser identificados lexicalmente como casos não sistemáticos.

É uma característica dos verbos transitivos terem uma passiva correspondente; entretanto, nem sempre há perfeita correspondência entre estruturas ativa > passiva de determinados verbos. Dessa forma, o verbo "haver" no sentido de "existir" na frase: "Há livros na estante"; por se tratar de oração sem sujeito, não tem como ocorrer transferência da ação de um agente para um paciente, porque não há um sujeito responsável por uma suposta ação, na verdade, não há nem mesmo uma ação. Outros verbos que também não admitem essa transformação são "levar" e "sofrer", em exemplos tais como: "A criança levou uma surra / O menor sofreu uma punição", porque já trazem em si uma noção de passividade. Há ainda outros verbos como "possuir", "ter" e "querer", embora classicamente sejam considerados como 
tendo objetos diretos, por não codificarem ação, não há transferência de um agente para um paciente, por isso, a impossibilidade de estruturas como: Ana possui uma gramática $>$ *Uma gramática é possuída por Ana / João tem uma bicicleta > *Uma bicicleta é tida por João / Os professores querem mudanças $>{ }^{*}$ Mudanças são queridas pelos professores.

Discordamos daquela abordagem, principalmente quanto à afirmação de que são exceções ou idiossincrasias os casos de estruturas que não se encaixam no modelo estabelecido pela teoria, pois se acaba tratando como exceções fenômenos que são comuns no uso efetivo da língua.

\section{Estrutura de passiva na perspectiva funcionalista}

Para o funcionalismo, cada parte do comportamento linguístico é ativada por um propósito comunicativo específico e a forma é determinada pela adequação na expressão desse propósito no interior da organização pragmática geral da comunicação.

A abordagem funcionalista fundamenta-se em dois princípios considerados universais, segundo Givón $(1991$; 1995). O primeiro é o princípio da iconicidade, que atua nas escolhas linguísticas no momento do discurso. A esse princípio associam-se outros três: o princípio da quantidade, pelo qual se postula que maior quantidade, menor previsibilidade ou maior importância de informação receberá mais material de codificação; o da integração, que compreende que conceitos cognitivamente mais integrados manifestam-se, linguisticamente, com maior integração morfossintática; e o da ordenação linear, pelo qual se entende que a ordenação das formas no nível oracional e de organização textual revela a ordem de importância para o falante.

O segundo princípio geral é o da marcação, que envolve uma relação sistemática entre complexidade estrutural e cognitiva. Sob esse princípio, categorias cognitivamente marcadas, isto é, cognitivamente complexas, tendem a ser também estruturalmente marcadas. A marcação, no entanto, não é absoluta, mas dependente do contexto e pode ser caracterizada por três critérios básicos. Pelo critério da complexidade estrutural, a estrutura marcada tende a ser mais complexa, maior; pelo critério da distribuição de frequência, a ser menos frequente; e, pelo critério da complexidade cognitiva, a ser mais complexa cognitivamente, demandando maior atenção, esforço mental e tempo de processamento.

Nessa perspectiva, a oração ativa é considerada a estrutura sintática mais básica, o padrão neutro, enquanto a passiva é identificada como uma estrutura complexa, o padrão marcado. Essa classificação como estruturas básicas e complexas é decorrente das propriedades formais das estruturas ativa e passiva. Sintaticamente, a ordem dos constituintes na estrutura de passiva desvia-se da ordenação prototípica: Sujeito - Verbo - Objeto, em que Sujeito e Objeto, em geral, correspondem aos papéis semânticos Agente e Paciente, respectivamente.

Assim, a estrutura de passiva também apresenta uma complexidade semântica, já que a oração ativa é mais básica porque o papel de agente tende a ser considerado como um papel semântico mais básico do que o do paciente.

Estudos funcionalistas confirmam que, na língua portuguesa, os elementos que funcionam como agente tendem a ocorrer na posição inicial da oração, ou seja, como sujeito e tópico, e os que têm papel de pacientes geralmente ocorrem na posição final, isto é, como objeto. A estrutura de passiva, entretanto, interfere nessa correspondência entre papéis semânticos e relações gramaticais, já que o objeto (paciente) de um verbo semanticamente transitivo é utilizado com a função de sujeito e tópico da oração, e o agente, por sua vez, é omitido ou configurado como um sintagma preposicionado. 
Shibatani (1985), por exemplo, parte do pressuposto de que as estruturas linguísticas não são isoladas, mas apresentam semelhanças parciais entre si. Com isso, centraliza a discussão não em torno da identificação da passiva, mas na determinação do quanto a estrutura aproxima-se da passiva prototípica, ao longo de um contínuo semântico. Adotando, assim, uma concepção não discreta da gramática, propõe-se a examinar as correlações entre passivas e outras construções, tais como as reflexivas, recíprocas e "passivas mediais" (que expressam a ocorrência de eventos espontâneos), em dados de variadas línguas como o japonês, o espanhol, o francês, entre outras, nas quais, tais construções partilham propriedades formais e semânticas com a passiva prototípica.

Para Shibatani (1985), a construção passiva serve a uma função semântico-pragmática completamente distinta da construção ativa transitiva. Essa função é a desfocalização do participante prototipicamente associado ao papel de agente. Para o autor, dizer João comeu a maçã não é o mesmo que dizer A maçã foi comida por João.

O autor respalda-se em Meillet (1948, p. 196), segundo o qual "o verdadeiro papel da passiva é exprimir o processo no qual o agente não é considerado". Shibatani (1985) afirma que geralmente as passivas não expressam o agente, demonstrando que línguas como o finlandês e o russo evitam a expressão do agente na estrutura de passiva. Nas línguas que permitem a expressão do agente, o autor observa que as passivas sem a expressão do agente são muito mais numerosas em dados reais do que aquelas com o agente expresso. Isso pode indicar que a construção passiva é usada quando a expressão ou a individualização do agente é impossível ou irrelevante (ou pressuposta).

Shibatani (1985) ressalta que uma oração sem um participante agente, ou algo próximo disso, como um experienciador, não permite passiva porque não há agente para desfocalizar. Segundo ele, a construção passiva implica a existência de um agente para o evento e sua conceptualização é a de um evento transitivo.

Nesse sentido, na construção passiva prototípica, o agente é parte da valência semântica, ou seja, ele está presente semanticamente, sendo desfocalizado no nível da codificação sintática. Assim, segundo o autor, passivas verdadeiras são semanticamente "transitivas", pois possuem tanto um agente quanto um paciente em seu esquema semântico.

Do que Shibatani (1985) afirma, destacamos em nossa análise a noção de que a construção passiva é usada quando a expressão do agente é pressuposta, uma vez que nas bulas de medicamento, em geral, o agente é o médico ou o próprio paciente.

Furtado da Cunha (2000, p. 108) também destaca que a complexidade da estrutura de passiva não se limita a questões exclusivamente sintáticas, já que as propriedades formais das orações ativas e passivas são originadas, até certo ponto, das propriedades do discurso e se correlacionam com o grau de pressuposicionalidade dessas estruturas.

Segundo a autora, a voz ativa, considerada o padrão neutro, distingue-se da voz passiva por ser menos pressuposicional que esta, categorizada como o padrão complexo. Pragmaticamente, a oração ativa é usada no discurso para transmitir grande parte da informação nova. Assim, a complexidade pressuposicional da passiva resulta do fato de que a maioria dessas estruturas envolve um agente pressuposto, identificável do contexto discursivo ou do conhecimento pragmático geral informado predominantemente por construções com a voz ativa. Isso significa que as orações passivas são mais marcadas em termos da sua pressuposicionalidade.

Essa característica pressuposicional da estrutura de passiva pode ser identificada como uma estratégia de organização textual para determinado interlocutor em uma determinada situação comunicativa, como observado 
em um estudo anterior (AMORIM; COSTA; ROCHA, 2012), cujo foco era a análise do uso de estruturas passivas no gênero manchete.

Além da complexidade sintática e semântica, a estrutura de passiva apresenta uma complexidade pragmática. A passiva é característica do uso mais formal da língua e sua frequência varia de acordo com a modalidade - escrita ou falada - e depende do gênero textual. Do conjunto de bulas analisadas, é possível verificar que aquelas direcionadas aos profissionais da saúde apresentam uma linguagem mais formal e com maior incidência de passiva em contraste com as bulas antigas e, principalmente, as voltadas aos pacientes, que se configuram em forma de diálogo (pergunta e resposta), nas quais a ocorrência de passiva é quase nula. A baixa ocorrência de passiva nas bulas direcionadas aos pacientes parece atender às exigências da ANVISA, no que se refere ao uso de uma linguagem mais clara e objetiva, a fim de garantir aos leitores o acesso à informação segura e adequada para uso racional dos medicamentos.

Para Givón (2001 [1984], p. 122), o padrão neutro, isto é, a voz ativa, é a referência pragmática funcional em relação à passiva. $O$ autor acrescenta que, na passiva, o agente é extremamente não tópico ('suprimido', 'rebaixado'), de modo que o paciente é o único argumento tópico na cláusula. O uso da passiva desloca a referência do agente, que perde seu status de tópico, para o paciente, que passa a ostentar esse status.

Furtado da Cunha (2000, p. 109) destaca que, no discurso, a tendência natural da comunicação é manter um mesmo referente como ponto de partida de uma série de sentenças. Sendo assim, a continuidade tópica reflete a norma na comunicação, ou seja, o padrão neutro, enquanto a mudança de tópico representa um desvio dessa norma, o padrão marcado. A autora acrescenta que se a troca de informação nova é a base do discurso humano, o padrão oracional ativo é o mais frequente no discurso. Desse modo, as construções mais pressuposicionais, as passivas, exibem maiores restrições distribucionais do que as construções neutras.

\section{Gêneros textuais: a bula de medicamento}

Considerando o uso efetivo da língua, é possível afirmar que esse uso não se limita a um mecanismo de representação ou descrição do mundo. Ao contrário disso, sabemos, como Bakhtin, que a língua é um instrumento social, histórico e cognitivo que nos permite agir e intervir em nosso meio. E essa inserção dos indivíduos é dada por meio da utilização dos diversos gêneros textuais - entidades sociodiscursivas que organizam as atividades comunicativas e que emergem no interior de uma situação definida, apresentando propriedades específicas (MARCUSCHI, 2003).

Marcuschi (2005, p. 95) assegura que a manifestação verbal ocorre sempre por meio de textos realizados em algum gênero e que a escolha de um ou outro gênero não é aleatória, mas subordina-se a interesses específicos. 0 autor acrescenta que os gêneros operam, em determinados contextos, como formas de legitimação discursiva, já que se situam entre desenvolvimentos históricos e práticas sociodiscursivas que se refletem na língua. Desse modo, é possível afirmar que cada gênero apresenta uma determinada estabilidade e define o que é dizível em determinado contexto situacional.

Assim, gêneros textuais podem ser definidos como quaisquer textos que cumprem uma finalidade social e que emergem no interior de uma situação definida, apresentando propriedades específicas (MARCUSCHI, 2003, p. 4).

A bula de medicamento é um dos diversos gêneros que circulam diariamente em nossas relações interdiscursivas, sociais e pragmaticamente determinadas. Esse gênero caracteriza-se por apresentar um texto cuja leitura pode ser feita por qualquer cidadão, provavelmente, quando necessita de orientações para usar corretamente um medicamento, a fim de cessar ou amenizar uma dor ou mal-estar. No entanto, muitas vezes, a compreensão das orientações e informações disponibilizadas nas bulas é prejudicada pelo 
uso de uma linguagem muito técnica, do grande volume de informações e do tamanho reduzido das letras.

Segundo Costa (2008, p. 46), na farmacologia, a bula é um texto "impresso que acompanha o medicamento e contém informações mais ou menos detalhadas sobre sua composição, utilidade, posologias, contraindicações etc." Tem uma linguagem técnica, formal, às vezes, bastante complicada para o leigo, embora na parte "informações ao paciente" procura-se valer de uma linguagem menos técnica.

A bula se constitui das seguintes partes:

(i) identificação do medicamento: nome, forma farmacêutica (pomada, creme...), uso e composição;

(ii) informações ao paciente: ação esperada do medicamento, riscos, modo de uso...

(iii) informações técnicas aos profissionais de saúde: características farmacológicas, indicações, contraindicações, posologia, advertências, armazenagem, interações medicamentais, reações adversas, superdosagem...

(iv) créditos: profissional responsável, laboratório/fabricante, endereço completo;

(v) informações sobre atendimento ao consumidor: endereços e telefones. (COSTA, 2008, p. 46)

A ANVISA disponibiliza aos laboratórios fabricantes de medicamentos um guia de redação de bulas, criado a partir de uma adaptação do texto $A$ redação de bulas para o paciente - um guia com os princípios de redação clara, concisa e acessível para o leitor de bulas, de autoria da Professora Celina Frade, Doutora em Linguística pela UFRJ, que teve sua primeira versão publicada em 2004 na página do E-bulas (ANVISA, 2009, p. 6).

Nesse guia, a bula é descrita como um tipo de texto (ou gênero) dirigido a dois públicos: o profissional de saúde e o paciente, sendo desenvolvido, usado e interpretado a partir de situações recorrentes definidas, as quais servem para estabilizar a experiência e dar a ela coerência e significado. A bula é um gênero considerado relativamente estável e regular em relação à forma e layout, mas dinâmico e variável quanto ao conteúdo e ao contexto da situação de uso em virtude da crescente descoberta de novos medicamentos, acréscimo de novas informações e das necessidades de seus usuários. Os responsáveis pelas informações contidas nas bulas são a indústria farmacêutica e as classes médica e farmacêutica.

0 que se espera dessas regularidades é que se tornem familiares, moldando-se o gênero através do uso repetitivo, para assim restringir possibilidades de variações e inovações textuais e, consequentemente, conduzir o leitor a uma interpretação mais convencional e adequada aos propósitos de seus produtores, replicando-se o modelo de leitura de uma bula para todas as demais. O referido guia ainda informa que, segundo pesquisas promovidas pela ANVISA, são identificados problemas de leitura de bulas tanto no modelo dirigido ao profissional de saúde quanto ao voltado ao paciente. Enquanto a bula dirigida aos profissionais de saúde apresenta falhas em relação a pouca informação do conteúdo, a bula dirigida ao paciente (o leigo) tem a leitura e compreensão dificultadas devido principalmente ao tamanho pequeno da letra, excesso de informação e de termos técnicos, frases longas, complexas e confusas, excesso de nominalização e uso predominante da voz passiva.

Para dirimir tais problemas e com o objetivo de atender às necessidades distintas de informações por parte de profissionais da saúde e leigos, a ANVISA determinou a reformulação dos textos de bulas de medicamentos, cujas regras estão dispostas na RDC 47/09, que obriga os laboratórios a prepararem dois tipos de bulas, ambos com informações mais claras, linguagem objetiva e conteúdos padronizados: uma voltada para o paciente, com linguagem mais simples, letras maiores e em forma de pergunta, e outra voltada para o profissional da saúde, com informações técnico-científicas. 
Segundo a Agência, as regras para bulas de medicamentos estão em processo de revisão desde 2008 e foram discutidas por meio da Consulta Pública em janeiro de 2009.

Quanto ao uso da linguagem, dentre as orientações do guia de bulas da ANVISA (2009, p. 6), há uma recomendação para se usar a voz ativa sempre que adequado. É apresentado como justificativa que os verbos na voz ativa, além de manterem a conexão entre o sujeito e o verbo mais próxima, acrescentam mais vigor e precisão à frase do que os verbos na voz passiva. Levantamos como pressuposição que, nas bulas novas direcionadas aos pacientes, a quantidade de construções passivas utilizadas é muito pequena, além de todas apresentarem um agente suprimido, mas pressuposto.

\section{Metodologia e análise dos dados}

Para analisarmos as estruturas de passiva das bulas de medicamentos elaboradas no Brasil em atendimento à RDC 47/2009, observamos as bulas de aproximadamente 30 (trinta) medicamentos. Para tanto, pesquisamos no site: www.anvisa.gov.br/bularioeletronico de onde coletamos as bulas para paciente e para profissionais da saúde. As bulas anteriores à regulamentação foram obtidas via e-mail.

A partir dessa observação, selecionamos 9 (nove) bulas para constituir o corpus deste trabalho que foram assim distribuídas: três tipos de bula para cada um dos três modelos selecionados (bula antiga, bula para paciente, bula para profissional da saúde). Foram escolhidas as seguintes marcas: Buscopan Plus, Cebion e Dramin.

Na análise, inicialmente fizemos uma comparação entre os três tipos de bula, observando as diferenças nas estruturas linguísticas utilizadas.

A ANVISA definiu, na RDC 47/09, que os textos de bula para pacientes devem ser organizados em forma de questionário, com blocos de informações básicas reunidas em torno de nove perguntas: 1. Para quê (sic) este medicamento é indicado?; 2. Como este medicamento funciona?; 3. Quando não devo usar este medicamento?; 4. O que devo saber antes de usar este medicamento?; 5. Onde, como e por quanto tempo posso guardar este medicamento?; 6. Como devo usar este medicamento?; 7. 0 que devo fazer quando eu me esquecer de usar este medicamento?; 8. Quais os males que este medicamento pode me causar?; 9 . 0 que fazer se alguém usar uma quantidade maior do que a indicada deste medicamento?

Durante a análise, constatamos que a normatização trouxe de fato regularidade ao gênero, observando-se que os três modelos selecionados para estudo, nas bulas de paciente, adotaram o modelo de linguagem empregado nas perguntas para desenvolverem o texto com as respostas, basicamente utilizando estruturas linguísticas muito semelhantes. Na primeira pergunta, por exemplo, nas bulas novas dirigidas a pacientes, dois laboratórios aproveitam-se da mesma estrutura utilizada no enunciado da questão para repeti-la na sua resposta, acrescentando apenas as indicações do medicamento: (1) "Buscopan Plus é indicado para (...)"; (2) "Dramin é indicado para (...)", divergindo apenas um pouco, e sem inovar, o enunciado da bula de Cebion: (3) "Este produto é um suplemento vitamínico indicado como auxiliar (...)".

Em (1) e (2), há duas possibilidades de análise: na primeira, o elemento "indicado" pode ser considerado adjetivo qualificativo com o sentido de "apropriado; adequado" e faz parte da estrutura de predicado nominal - "Dramin é indicado (apropriado; adequado) para prevenir e tratar...." É possível ainda inserir alguns advérbios: "Dramin é (muito/bastante/ totalmente) indicado (apropriado; adequado) para prevenir e tratar...., o que corrobora essa análise. Na segunda análise, o elemento "indicado" pode ser considerado particípio, empregado no sentido de "apontado; recomendado" e diferentemente da proposição anterior, faz parte da estrutura de 
predicado verbal - "Dramin é indicado (apontado; recomendado) por (agente pressuposto), visto que só o médico pode ser o agente de "apontar e recomendar".

Em (3), na bula do Cebion, há a seguinte informação: "Este produto é um suplemento vitamínico indicado como auxiliar (...)". O fato de haver a inserção de "um suplemento vitamínico" entre o verbo "ser" e o elemento "indicado" e, posteriormente, os elementos "como auxiliar" parecem favorecer a análise do elemento "indicado" como particípio, com o sentido de "apontado; recomendado".

Na segunda questão, onde é empregada estrutura ativa com o verbo no presente (Como este medicamento funciona?), observa-se, no texto de resposta, o predomínio de estruturas linguísticas similares ao do enunciado da questão, ou seja, o uso de construções ativas com verbos no presente do indicativo: "promove, diminui, alivia" (Buscopan Plus), "corrige, estimula, supre" (Cebion), "contém, controla, inibe" (Dramin).

As únicas estruturas passivas empregadas para responder ao segundo questionamento registram-se na bula do Dramin: "Não é conhecido com exatidão o mecanismo pelo qual DRAMIN ${ }^{\circledR}$ controla os enjoos, vômitos e tonturas de diversas origens, mas admite-se que inibe diretamente o centro do vômito e as funções do labirinto no cérebro". Neste caso, foram utilizadas as formas analítica e pronominal da voz passiva, ocorrendo o apagamento do agente, facilmente recuperável no contexto a partir do conhecimento enciclopédico dos leitores sobre o mundo da ciência e da pesquisa, a indústria farmacêutica e os papéis das classes médica e farmacêutica. Por esse motivo não é necessário explicitar o agente da passiva também na resposta à primeira pergunta, pois os leitores facilmente inferem os agentes que indicam o medicamento. Tal apagamento se justifica em face do caráter de pressuposicionalidade das construções passivas, ou seja, trazem um agente pressuposto.
Nas novas bulas para profissionais de saúde, observa-se um caso interessante para reflexão sobre a natureza pragmática do apagamento do agente da passiva. Ao descrever as propriedades farmacológicas do paracetamol (bula de Buscopan Plus), declara-se que o medicamento é "completamente absorvido pelo intestino delgado", mas não se explicita que mecanismo o distribui para os tecidos, afirmando-se apenas que "O fármaco é rápida e uniformemente distribuído para os tecidos". Tal apagamento na descrição de propriedades de um medicamento qualquer pode ocorrer por motivações distintas, entre as quais enumeramos algumas: a) $O$ detalhamento da informação não é relevante para os propósitos comunicacionais do texto; b) A descrição das informações seria muito extensa ou complexa, podendo ser prescindida sem prejuízo ao texto; ou c) Os pesquisadores não dominam o conhecimento necessário para fornecer informações precisas e detalhadas sobre a medicação, seu funcionamento ou propriedades.

Outro aspecto importante do apagamento do agente da passiva pode ser observado no modelo novo de bula para pacientes de Buscopan Plus, em que o conhecimento de mundo do leitor é que determina sua capacidade de produzir adequada inferência em casos de omissão do agente ou agentes da passiva. Na referida bula, afirma-se, com uso de uma construção passiva, que o "uso intenso e prolongado de substâncias analgésicas (como o paracetamol) pode provocar dores de cabeça, que não devem ser tratadas com doses maiores da medicação". O apagamento do agente da passiva se dá porque é possível realizar-se a leitura de forma pragmática, inferindo o leitor, de modo convencional e adequado, que a posição de agente tanto pode ser ocupada pelo médico quanto pelo paciente, uma vez que nem o médico pode continuar tratando das dores de cabeça com aumento da dosagem nem o paciente pode se automedicar, tomando mais comprimidos por sua conta, sem investigar, junto com seu médico, por que as dores persistem com a dose normalmente indicada. Seria interessante quando há uma preocupação em 
educar e informar as pessoas através dos meios de comunicação e na escola, incluindo nessa tarefa, a de alertar quanto aos perigos da automedicação, portanto existe também uma expectativa de se produzir esse tipo de compreensão leitora do texto da bula.

Já na construção seguinte dessa mesma bula, em "O tratamento deve ser descontinuado nos primeiros sinais de reação alérgica”, embora o apagamento possa se referir aos dois agentes: médico e paciente, a responsabilidade de descontinuar o uso do medicamento compete ao paciente, que deve estar atento aos primeiros sinais de reação alérgica. Apenas em um segundo momento a ação de descontinuar aplica-se ao médico, que certamente, numa nova consulta, informado sobre as reações alérgicas do paciente, indicará uma medicação alternativa para dar continuidade ao tratamento.

No gênero bulas, há agentes preestabelecidos e elementos a eles relacionados que se alternam ao longo do texto na posição de tópico em estruturas ativas e passivas, ocorrendo, em alguns casos, o apagamento ou ênfase do agente nas passivas tendo em vista objetivos funcionais e pragmáticos do texto. Pressupõe-se que o texto das bulas está a falar dos cientistas pesquisadores, dos responsáveis pelos laboratórios e resultados das pesquisas, do médico, dos pacientes, do medicamento e seus componentes, cujos princípios são tidos como "ativos". Salienta-se, porém, que o apagamento por pressuposição não ocorre somente em estruturas linguísticas com uso da passiva. Curiosamente, ao principal elemento topicalizado da bula (o medicamento), vão ser adicionadas palavras e expressões em função metonímica, tais como comprimidos, embalagens, solução oral, pois, pressuposto, apaga-se o nome do medicamento e a forma de apresentação (em drágeas ou líquido), ou a embalagem em si. Um exemplo da nova bula de Buscopan Plus para profissionais da saúde: "Comprimidos revestidos: embalagens com 20 e 120 comprimidos revestidos". Não é necessário enunciar "Comprimidos revestidos de Buscopan Plus", pois tal informação está pressuposta pelo gênero, pela situação e pelo contexto comunicacional e de uso da língua.

Os elementos preestabelecidos, portanto, geralmente pressupostos, do gênero bula se revezam na função sintática de sujeito e objeto nas construções ativas, apagando-se ou não quando se transformam as orações para construções passivas. Se em alguns casos o apagamento da passiva se dá por conta da pressuposicionalidade ou desconhecimento do agente, em outros, o apagamento não poderá ocorrer, tendo em vista a necessidade de explicitá-lo: "Este medicamento não deve ser utilizado por mulheres grávidas” (Dramin). Em casos como este, preteriu-se a estrutura ativa porque o gênero bula, com o uso da construção passiva, topicaliza o medicamento e não o usuário. Esse enunciado talvez não obtivesse o mesmo efeito pragmático se se apresentasse assim: "Mulheres grávidas não devem utilizar este medicamento".

Em termos pragmáticos, a construção ativa, ao se iniciar com o agente Mulheres grávidas, poderia levar a um desvio da atenção ou interesse de leitura dos pacientes que não se encaixassem nessa categoria. Todavia, optando-se pela estrutura passiva, a linearidade do texto conduz sintaticamente à topicalização do medicamento e à assimilação integral da informação, favorecendo que o leitor se descarte da necessidade de seguir a recomendação somente ao final da leitura, ao concluir que a recomendação não se aplica a seu caso por não ser mulher ou não estar grávida.

Outra observação quanto às estruturas linguísticas utilizadas refere-se à escolha do produtor da bula quanto a utilizar o imperativo ou a modalização em construções ativas ou passivas, com objetivo de informar sobre resultados de pesquisa, alertar sobre efeitos colaterais do medicamento, instruir sobre perigos relativos à interação medicamentosa, orientar procedimentos ou esclarecer sobre o uso da medicação, como em: “(...) avise seu médico, pois ele pode considerar reduzir a dose de DRAMIN ${ }^{\circledR}$, em que a decisão a tomar 
cabe ao médico, ou em contextos em que a decisão compete ao paciente, como em: "DRAMIN ${ }^{\circledR}$ pode ser tomado imediatamente antes ou durante as refeições". Constata-se arbitrariedade no uso das estruturas, pois, enquanto no caso de proibições ocorre o imperativo em: "Não tome este produto se você sofre de cálculos renais" (Cebion), há modalização na bula de outro medicamento: "Você não deve usar BUSCOPAN PLUS se tiver alergia aos princípios ativos ou a qualquer outro componente da fórmula".

\section{Conclusões}

Este estudo aponta para o postulado do funcionalismo sobre o caráter determinante da motivação discursivo-pragmática para o uso das estruturas linguísticas. Procuramos observar essa relação nas construções passivas, refletindo sobre a natureza pragmática do apagamento do agente, quando o texto das bulas adotava tais construções.

Embora as construções passivas sejam evitadas nos novos modelos de bula, uma vez que o guia da ANVISA (2009) para elaboração dos textos pelos laboratórios recomende o uso da ativa sempre que adequado, observamos que, em determinadas situações, a estrutura passiva é a mais adequada para atingir o objetivo comunicacional e pragmático. A estrutura passiva viabiliza a topicalização de informações sobre o medicamento, tais como suas indicações, a forma de administrar a medicação, a apresentação de recomendações ou proibições ao paciente, dentre outras informações, em que ocorre com frequência o apagamento do agente, facilmente pressuposto (o médico, a indústria farmacêutica, os resultados de pesquisas efetuadas pelos laboratórios, etc.), que não se constitui na informação principal a ser comunicada.

No caso específico do gênero bula, a análise do corpus em questão neste estudo permitiu verificar que o apagamento do agente nas estruturas de passiva depende, além de condições de natureza sintática e semântica do componente a ser suprimido, também do fator pragmático envolvido, a exemplo do que ocorre em outros gêneros textuais. Salientamos, portanto, casos em que o apagamento do agente não é possível, pois impede o objetivo comunicacional pretendido pelo texto, pois é justamente a ênfase do agente que permite ao leitor descobrir a conduta a ser adotada pelos diferentes pacientes em relação ao medicamento, como ocorre em "Este medicamento não deve ser tomado por mulheres grávidas".

\section{Referências}

ABREU, Antônio Suárez de. Gramática mínima: para o domínio da língua padrão. 2. ed. São Paulo: Ateliê, 2003.

AMORIM, Carmelita Minelio da Silva; COSTA, Maria José; ROCHA, Lúcia Helena Peyroton. Estratégias de apagamento do agente no gênero manchete: um olhar funcionalista. Revista Saberes Letras, v. 10, p. 27-47, 2012.

ANVISA DISPONIBILIZA NOVAS BULAS NO BULÁRIO ELETRÔNICO. Sala de imprensa, 18 de abril de 2012. Disponível em: <http://portal.anvisa.gov.br/wps/content/ anvisa+portal/anvisa/sala+de+imprensa/menu++noticias+anos/2012+noticias/anvis a+disponibiliza+novas+bulas+no+bulario+eletronico>. Acesso em: 20 dez. 2012.

BECHARA, Evanildo. Moderna gramática portuguesa. 37. ed. Rio de Janeiro: Lucerna, 1999.

CHOMSKY, Noam. Syntactic Structures. The Hague: Mouton, 1957.

. Lectures on Government and Binding. Dordrecht: Foris Publications, 1981.

COSTA, S. R. Dicionário de gêneros textuais. Belo Horizonte: Autêntica, 2008.

FURTADO DA CUNHA, Maria Angélica. A complexidade da passiva e as implicações pedagógicas do seu uso. Linguagem \& Ensino, v. 3, n. 1, p. 107-116, 2000.

GIVÓN, Talmy. Serial verbs and the mental reality of "event": grammatical vs. cognitive packaging. In: TRAUGOTT; HEINE. (Eds.). Approaches to grammaticalization. Amsterdam/ Philadelphia: John Benjamins Publishing Company, 1991. Vol. 1, p. 81-127.

Functionalism and grammar. Amsterdam/Philadelphia: John Benjamins, 1995. 
GIVÓN, Talmy. Syntax: a functional typological introduction. v. 1. Amsterdam: John Benjamins, 2001[1984].

HEINE, B. Auxiliaries: cognitive forces and grammaticalization. New York/Oxford: Oxford University, 1993.

IGNÁCIO, Sebastião Expedito. Análise sintática em três dimensões: uma proposta pedagógica. Franca: Ribeirão Gráfica e Editora, 2002.

LANGACKER, Ronald. The english passive. Concept, image and symbol: The Cognitive Basis of Grammar. Mouton de Gruyter, 1990. Cap. 4.

MARCUSCHI, Luiz Antonio. A questão do suporte dos gêneros textuais. 2003 (mimeo).

Produção textual, análise de gêneros e compreensão. 2005 (mimeo).

MEILLET, Antoine. Linguistique historique et linguistique générale. Paris, 1948.

MINISTÉRIO DA SAÚDE. Bulário eletrônico da Anvisa. Disponível em: <http://www4. anvisa.gov.br/BularioEletronico/>. Acesso em: 15 nov. 2012.

SAID ALI, Manuel. Gramática histórica da língua portuguesa. 3. ed. Brasília: Editora da Universidade de Brasília, 1964.

SHIBATANI, Masayoshi. Passives and related constructions: a prototype analysis. Language, v. 61, n. 4, p. 821-848, 1985. http://dx.doi.org/10.2307/414491

Recebido em 20/04/2015.

Aceito em $23 / 07 / 201$ 